\title{
LAS MENTIRAS DE LA VERDAD Y EL PERIODISMO COMO AUTODESTRUCCIÓN
}

\begin{abstract}
Alberto Fuguet
Una de las "piedras de toque" de la obra de Mario Vargas Llosa es su tesis de "la verdad de las mentiras", aunque al parecer - sostiene en este artículo el escritor y cineasta (y fan del autor peruano) Alberto Fuguet-, Vargas Llosa no ha mentido tanto. O si lo ha hecho, ha sido de una manera adelantada, muy contemporánea, sobre todo en novelas como Conversación en La Catedral y La tía Julia y el escribidor que fusionan mucha creación (mentiras) con verdades puras y duras, además de ser libros extremadamente pop e híbridos. Fuguet también escudriña en el que, para él, es quizás su mejor libro (El pez en el agua), una novela de no-ficción o un libro de memorias donde Vargas Llosa revela mucho acerca de la creación de sus primeros libros y una suerte de "pánico" y "obsesión” por la figura del periodista y el escritor-en-ciernes que se pierde ahogado en el alcohol, la bohemia, las prensas y la misma ciudad de Lima.
\end{abstract}

Alberto Fuguet (Santiago, Chile, 1964). Escritor y cineasta. Licenciado en Comunicación Social de la Universidad de Chile. Profesor de la Universidad Diego Portales. Autor de las novelas Mala onda (Planeta, 1991), Tinta roja (Alfaguara, 1996) y Missing: Una investigación (Alfaguara, 2009). Entre sus filmes figuran "Se arrienda", "Velódromo" y "Música campesina" (2011). El 2010 obtuvo la Beca Guggenheim. Es colaborador estable de revista Qué Pasa.Fuguet@cinepata.com.

Estudios Públicos, 122 (otoño 2011). 


\section{A}

ntes de partir, a modo de introducción de alguien que, sobre todo desde octubre del 2010, no necesita mucha presentación: Vargas Llosa, digan lo que digan, analicen lo que analicen, cotillen lo que cotillen, les duela lo que les duela, es Vargas Llosa. Lo que no es poco. No hay otro y, para alivio y maldición de sus menores, no habrá otro. Es una marca, sí, pero es más que eso: es un universo, un mundo, una moral, un continente. Pocos en español le han llegado cerca y aun así tienen calles, salones VIP, rotondas y monumentos. Vargas Llosa no sólo ha publicado una decena de novelas formidables, ha creado a partir de un mundo real (casi siempre su own private Perú limeño) un mundo propio que es inimitable y, lo que es quizás más importante, es inconfundible. Le devolvió la dignidad y la magia al realismo. El deicida, al final, quizás sea él y no tuvo que recurrir al realismo mágico para separarse de sus pares y de la tradición "telúrica" que lo traumaba cuando estaba partiendo y no tenía claro a qué tradición adscribirse.

Vargas Llosa, además, es uno de los peruanos más famosos del mundo y uno de los intelectuales latinoamericanos más respetados/vilipendiados del continente. Sus ensayos e incluso opiniones a la prensa son su "lado B". A veces parecen su lado "A". Casi quemó su carrera literaria al postular a la presidencia de su país. Es tal su incontinencia por opinar y criticar y poner en su lugar todo lo relacionado con el poder y las ideas en las cuales cree (y que sin dudas están dentro de su obra: pocas obras han sido tan antitotalitarias y pro-liberales) que, aún hoy, en que está relativamente "reivindicado" ante una "masa crítica cultural", sigue "manejando mal" su carrera pública al arriesgarse demasiado hasta convertirse más en un referente y una figura pública que en un escritor a secas. Y quizás la razón es simple: no es sólo un escritor, y es justamente esa dispersión (política, política, política, cine, teatro, periodismo, charlas) lo que lo convierte en lo que es.

A Vargas Llosa le gusta rockear, molestar, provocar. Sabe que muchos neoliberales que van a sus charlas no lo han leído o, a lo más, leyeron y no entendieron La casa verde en el colegio. Sabe que la gente que más lo admira no ha pasado de Los jefes o vio en DVD la adaptación de Pantaleón y las visitadoras con Angie Cepeda. Pero también sabe que tiene lectores cautivos y que, en el mundo intelectual, lo si- 
guen con lupa, línea a línea. Sea lo que sea, pase lo que pase, Vargas Llosa es inmenso incluso cuando es menor (¿El hablador?). Ganó el Nobel, sí, pero como buen grande, ha abierto las puertas para los que lo sigan después. Las influencias de Vargas Llosa quizás recién se verán y se entenderán muchísimos años después. Los caminos que ha pavimentado han sido claves: desde apostar por sus mundos (aunque sean burgueses); el interés por la adolescencia en un continente literario donde todos son mayores; la noción del zeitgeist y la necesidad y la urgencia de "captar su tiempo"; y, algo no menor, el uso de lo pop asumiéndolo como parte de la cultura (alta y baja) que nos rodea.

Vargas Llosa es, entre otras muchas cosas, un hombre del siglo $20 \mathrm{y}$, de pronto, capaz que tenga algo del 21 también. Tanto que incluso autores contemporáneos suyos (y contemporáneos míos) pueden quedar del todo asombrados cuando capten que una cosa es lo que está en su obra y otra es lo que está o creen que está en sus declaraciones. Vargas Llosa quizás tiene la culpa de lo mal leído que ha sido por la gente que mejor capacidad tiene para leer un texto: los académicos. Yo una vez enseñé sobre Vargas Llosa, en la UCLA, en un curso de literatura latinoamericana del siglo 21, y sus libros eran claramente los predecesores. Entre tanto Bolaño y Diamela Eltit, a veces la academia se olvida que Vargas Llosa no sólo es una figura mediática-política-pop sino también un autor de primer orden. De existir McOndo, Vargas Llosa claramente ya es uno de los padres (abuelos) fundadores. ¿Hay novelas más postmodernas y contemporáneas que La tía Julia y el escribidor o Pantaleón y las visitadoras? Su interés por la cultura pop $\mathrm{y}$, digamos, trash, es asombrosa y, quizás escondida dentro de novelas donde a veces la arquitectura terminaba robándose la película, sin duda nos habla de un artista que, por mucho que estaba obsesionado y quizás hasta fijado en Europa y su cultura, es y será americano en el mejor y peor de los sentidos (de Los cachorros, 1967: "Empezó a ponerse corbata y saco, a peinarse con montaña a lo Elvis Presley [...]”; "¿a que nos invitaba al Oh, Qué Bueno y hacíamos perro muerto?, a que no hermano, y ellos iban al Oh, Qué Bueno, nos atragantábamos de hamburgers y de milk shakes $[\ldots]$ ".

Vargas Llosa como su país y su continente es mestizo, híbrido, desordenado, incontrolable y vengativo. La misma persona, lúcida y civilizada que sorprende a todo el mundo por su familiaridad con la civilización occidental, se regocija en temas extremadamente locales y 
dignos de una república bananera (colegios militares, radioteatros, prostíbulos y prostitutas, niños ricos privilegiados, guerrilleros en ciernes, prensa roja) y — quizás sin darse cuenta — los salpica de la cultura pop del pueblo.

\section{2}

En efecto: Vargas Llosa fue uno de los primeros en América Latina en fijarse en los supuestos subgéneros basura como el radioteatro, o en centrar un buen trozo de su obra en torno al periodismo, profesión que asocia con el camino a la perdición. Al menos, al early, mostpersonal VLl este pavor a quedarse en una redacción, a gastar su tinta en el papel que al día siguiente sirve para envolver pescados, es algo que aparece una y otra vez. El periodismo es un lupanar ágrafo donde, quizás, un escritor puede aprender algunos tics y trucos, pero es un sitio peligroso, pues termina carcomiendo toda posibilidad de concretar una obra. Los periodistas y escribidores, o aquellos intelectuales, universitarios inquietos o escritores en ciernes que no son capaces de huir del periodismo y de la mediocridad del "mundillo cultural" local, terminan alcoholizados y, para peor, sin obra o sin resonancia fuera de su círculo. El periodismo se cuela y a veces domina mucha parte de su obra: está en Historia de Mayta y está, por cierto, en El pez en el agua, que no sólo son sus memorias sino una suerte de diario in situ que es "previo" o contemporáneo de sus libros más notorios. Esto convierte este libro en clave: es una suerte de "making of", de diario creativo, que se escribió y publicó décadas después de que se publicaron esos libros cumbres. El periodismo cruza y sostiene Conversación en La Catedral y La tía Julia y el escribidor; y, en menor grado, parte del material con que armó El hablador y Travesuras de la niña mala tiene olor a tinta. El hombre que una vez destrozó por escrito una novela de Manuel Puig terminó escribiendo novelas extremadamente híbridas, pop, mediáticas, adelantadas a su tiempo, como Pantaleón y las visitadoras y ese perfecto pero maldito "reportaje periodístico" que es Historia de Mayta. Incluso en su segunda etapa, por desgracia menos personal y autobiográfica y, quizás por eso mismo, menos intensa, le ha dado un peso inusual a la novela histórica y ha novelado la crónica utilizando libros de otros autores y hechos históricos "auténticos" para intentar hacer la novela definitiva de temas en apariencia lejanos: La guerra del fin del mundo, La fiesta del 
Chivo, El Paraíso en la otra esquina y El sueño del celta son todas novelas que perfectamente pueden ser tildadas como "novelas-sampling", remixes de historias y libros y leyendas y datos y hechos históricos que, al pasar por el filtro de Vargas Llosa, terminan siendo la historia definitiva. Casement, Gauguin, Trujillo ahora son personajes de la obra de Vargas Llosa más que de sí mismos.

Para ser un hombre de otra generación, de más de 75 años, de esos que no ventilan sus miserias y anécdotas en charlas o conversaciones uno-a-uno (hace poco declaró que jamás ha ido o iría a terapia o al siquiatra), impresiona - al menos me impresiona a mí- que el hombre que acuñó la idea de "la verdad de las mentiras" terminó usando como materia prima mucha verdad (una verdad casi impúdica y hasta quizás hiriente) que casi no transformó en mentira: La ciudad y los perros; $L a$ tía Julia y el escribidor, y, claro, Conversación en La Catedral. La tía Julia Urquidi terminó siendo la Tía Julia y no la Tía Irene o la Tía Chela. En el caso de La tía Julia, libro clave y mayor de su obra aunque no necesariamente el más aplaudido o analizado, Mario Vargas Llosa se colocó no sólo como narrador y personaje principal sino que, quebrando todas las leyes imperantes en nuestras letras pero también en "nuestro protocolo de las buenas maneras", se bautizó "Marito" para terminar en "Varguitas" en vez de "Sotito" o "Sepulvedita". La tía Julia y el escribidor, en ese sentido, es un libro radical, acaso asesino, por momentos tan demente en su parte realista como en sus recreaciones de los teleteatros entre gore y kitsch, definitivamente pulp, tanto que quizás aún no se entiende del todo. ¿Cómo habrá sido recibida? Pues como un escándalo hoy difícil de sopesar pero que terminó con un libro "aclaratorio" de la aludida (Lo que Varguitas no dijo) escrito como forma de poner las cosas en su lugar por la misma persona a quien el libro está dedicado: "A Julia Urquidi Illanes, a quien tanto debemos yo y esta novela". Ahora que se sabe todo de la gente, no de la cual uno quiere saber, pero que provoca el deseo y el morbo en los demás "porque es verdad", Vargas Llosa entendió que para su "liviana" novela de formación, donde la mitad del libro sería una ficción tan llevada al límite que su gracia era justamente que no fuera creíble, la parte concerniente a aquello inspira- 
do en su propia biografía debía cargar los dados. Da lo mismo que nunca existió realmente Pedro Camacho, pero si colocaba que se casó con una tía mucho mayor que él, la novela dejaba de ser tan mentira como que todo - partiendo por los inventos - terminara pareciendo verdad. En un prólogo escrito más de veinte años después para la edición definitiva de La tía Julia y el escribidor, en la Colección Vargas Llosa de Alfaguara, MVLl explicó su experimento:

Comencé esta novela en Lima, a mediados de 1972 y la seguí escribiendo, con múltiples y a veces largas interrupciones, en Barcelona, República Dominicana, Nueva York, y de nuevo Lima, donde la terminé cuatro años después. Me la sugirió un autor de radioteatros que conocí de joven, al que sus melodramáticas historias devoraron el seso por un tiempo. Para que la novela no resultara demasiado artificial, intenté añadirle un collage autobiográfico: mi primera aventura matrimonial. Este empeño me sirvió para comprobar que el género novelesco no ha nacido para contar verdades, que éstas, al pasar a la ficción, se vuelven siempre mentiras (es decir, unas verdades dudosas e inverificables). Me costó trabajo dar una forma aceptable a aquellos episodios que, sin serlo, parecieran los guiones de Pedro Camacho, y volcar en ellos los estereotipos, excesos, cursilerías y truculencias característicos del género, tomando la distancia irónica indispensable pero sin que se volvieran caricatura. El melodrama ha sido una de mis debilidades precoces, atizada por las desgarradoras películas mexicanas de los años cincuenta, y el tema de esta novela me permitió asumirlo, sin escrúpulos. Las sonrisas y burlas no llegan a ocultar del todo, en el narrador de este libro, a un sentimental propenso a los boleros, las pasiones desaforadas y las intrigas de folletín.

Quizás su célebre ensayo/libro La verdad de las mentiras es más una gran frase (concisa, brillante, provocadora) que algo que, durante años, sus fans han tomado como dogma. Dicho de otra manera, su "La verdad de las mentiras" speech quiere decir (por lo que entiendo, pues tiene algo de trabalenguas) algo así como que la literatura, al final de cuentas, es la suma de una serie de mentiras o mentirillas (inventos, exageraciones, mutaciones) que conforman y crean y potencian realidades más sutiles y profundas y mejores que las "verdades" que no han tenido la suerte de pasar "por el colador". En un blog-bitácora peruano titulado http://marioelescribidor.blogspot.com que se dedicó a recopilar 
mucho material acerca de la obra del flamante Premio Nobel local, Silvio Rendón se detiene en el tema éste de "la verdad" y "las mentiras":

Si la tía Julia se queja por la forma en que ella es representada en La tía Julia y el escribidor, Mario Vargas Llosa la presenta como una desubicada que no entiende que se trata de una ficción; es literatura y por definición ésta tiene que ser ficticia. Si alguien critica la forma falsa en que se presenta algún hecho registrable en la obra vargasiana, resulta que esa persona no sabe de qué está hablando pues el escritor se toma licencias válidas para tergiversar la realidad a su antojo, como cuando un escultor juega con la arcilla.

La supuesta arcilla que ha utilizado Vargas Llosa ha sido alterada, pero es barro y se ha ensuciado las manos y salpicado a los otros. MVLl, tratando de explicar, en el prólogo de La verdad de las mentiras - su ensayo acerca de novelas clave en su formación literaria-, qué implica mentir y el poder que puede tener una mentira con el peso de la verdad, escribe lo siguiente:

¿Qué quiere decir que una novela siempre miente? No lo que creyeron los oficiales y cadetes del Colegio Militar Leoncio Prado, donde - en apariencia, al menos - sucede mi primera novela, La ciudad y los perros, que quemaron el libro acusándolo de calumnioso a la institución. Ni lo que pensó mi primera mujer al leer otra de mis novelas, La tía Julia y el escribidor, y que, sintiéndose inexactamente retratada en ella, ha publicado luego un libro que pretende restaurar la verdad alterada por la ficción.

Vargas Llosa, de nuevo, justificando la mentira/ficción, en el mismo prólogo:

La ficción es un sucedáneo transitorio de la vida. El regreso a la realidad es siempre un empobrecimiento brutal: la comprobación de que somos menos de lo que soñamos. Lo que quiere decir que, a la vez que aplacan transitoriamente la insatisfacción humana, las ficciones también la azuzan, espoleando los deseos y la imaginación.

Mi impresión es que, en su primera etapa, Vargas Llosa no miente tanto (aunque sin duda exagera y manipula como tiene todo el derecho de hacerlo) y siente la necesidad imperiosa de anclar esas mentiras 
o inventos indispensables en hechos y nombres y lugares, para justificar y acaso para aumentar el morbo de sus propios inventos. Vargas Llosa nunca necesitó de un Macondo o de una Santa María (García Márquez y Onetti: dos autores muy distintos a él y a los que sin embargo les dedicó dos notables ensayos) para sentirse libre y a sus anchas. Adecuó Lima a sus necesidades, pulsaciones y recuerdos (la Lima de Vargas Llosa es una Lima burguesa que se fue), lo mismo que hizo luego con sitios como Piura o Iquitos o el nordeste brasilero o Ciudad Trujillo, hoy Santo Domingo.

Lo ha dicho mil veces y lo dice en el prólogo de La tía Julia y el escribidor, pero insisto: creo que él mismo siente que más que las mentiras manipuladas que se pueden transformar en verdad, lo que realmente le importa y hace es manipular la verdad y pasarla por el cedazo de la imaginación, la memoria y la exageración, para que sea mejor y así transformarla en una verdad mayúscula. ¿Sino para qué usar tantos sitios reales, tantos nombres existentes, tanta referencia pop? Mucho placement limeño: el Cream Rica del Jirón de la Unión, el Bransa, el Grill Bolívar, el Club Terrazas, la boîte Negro-Negro, sitios que se repiten una y otra vez. Vargas Llosa es quizás nuestro primer autor de no-ficción, nuestro Truman Capote, un tipo que sobregira y colorea la verdad para que sea más verdad. De ahí lo potente de sus libros "personales", sean estos ficción o no. Vargas Llosa en el fondo es malo para mentir y sólo estalla cuando usa su propia verdad. Por algo fue tan mal político: antes que se usara el término "narración", Vargas Llosa se estaba "narrando" hace rato. Y quizás por eso el factor verdad emocional" es mucho más potente en sus primeros libros que en los libros más ficticios o, al menos, ajenos: El Paraíso en la otra esquina, por ejemplo. O, si sigo con ejemplos, por qué funciona tan bien (porque parece ser verdad) un libro "menor" como Travesuras de la niña mala que, claramente, está anclado en su propia biografía, viajes y vivencias.

\section{4}

Muchos años antes de que escribiera El pez en el agua, su notable libro de no-ficción que es bastante más que sus memorias, y quizás de ahí su intensidad, Vargas Llosa, que cree tanto en la ficción, empezó a desarmarla para ir creando una serie de "novelas de no-ficción" donde 
legendarios personajes periodísticos de la bohemia limeña de los 50 , como un tal Becerrita (en la vida real), aparecen con el mismo nombre en Conversación en La Catedral. ¿Perdón? No, no se trata de un "cameo", una mención al pasar, una suerte de guiño u homenaje. Becerrita interactúa con el joven aspirante a escritor Varguitas, que es y no es, fue y no fue, el propio Vargas Llosa. En El pez en el agua, que es donde Vargas Llosa supuestamente "no miente" (son "sus memorias" y, dicho sea de paso, le creo que lo son y si hubiera que medir "la veracidad" o "la pureza" de texto, creo que supera el 98\%), escribe esto acerca del mítico reportero de La Crónica:

[...] Becerrita me deslumbraba. Me parecía salido de una turbadora novela sobre los bajos fondos.

$[\ldots]$ en el mes que trabajé a sus órdenes también llegué a sentirme orgulloso de formar parte de su equipo.

[...] Becerrita era un trabajador incansable, tenía por su oficio una pasión desenfrenada, una fijación. Nada más parecía interesarle en el mundo, fuera de esos festines sangrientos, que nosotros, sus peones, íbamos coleccionando día y noche en nuestros recorridos por las comisarías de los barrios peor afamados de Lima $[\ldots]$.

Años antes, bastantes años antes en rigor (veinticuatro años separan al Becerrita de ficción del Becerrita "real"), en Conversación en La Catedral, Santiago Zavala (el álter ego de VLl) termina trabajando en La Crónica (un diario real, donde trabajó VLl) junto a un tal Becerrita:

Era lo más auténtico que pasó por el periodismo limeño — dijo Carlitos-. La mugre humana elevada a su máxima potencia, un símbolo, un paradigma. ¿Quién no lo va a recordar con cariño, Zavalita?

Vargas Llosa recordaba sí, con cariño y con precisión. Nunca fue hijo del senador Zavala, pero ese afán de llenar de verdades incuestionables sus mentiras lo hizo no sólo para confundir sino para potenciar su ficción. Este trozo, que parece de Conversación, sin embargo, de nuevo, es de El pez en el agua:

[E]ntrevistas a cantantes, empresarios de circo, toreros, sabios, excéntricos, bomberos, profetas, ocultistas y todas las actividades, quehaceres o tipos humanos que por una razón u otra merecían ser noticia. Tenía que ir de un barrio a otro de 
Lima, en una camioneta del diario, con un fotógrafo, a veces el mismo jefe de los reporteros gráficos, el gran Ego Aguirre, si el asunto lo justificaba. Cuando volvía a la redacción estaba en su punto. Una espesa nube de humo sobrevolaba los escritorios y las máquinas tecleaban. Olía a tabaco, a tinta y a papel. Se oían voces, risas, carreras de los redactores que llevaban sus cuartillas a Aguirre Morales, quien, lápiz rojo a la mano, las corregía y despachaba a talleres.

La llegada del jefe de la página policial, Becerrita, era el acontecimiento de cada noche. Si venía sobrio, cruzaba mudo y hosco la redacción hasta su escritorio, seguido por su adjunto, el pálido y rectilíneo Marcoz. Becerrita era bajito y fortachón, con los pelos engominados y una cara cuadrada y disgustada de perro bulldog, en la que destacaba, trazado a cordel, un bigotito linear, una hebra que parecía pintada con carboncillo. El había creado la página roja - la de los grandes crímenes y hechos delictuosos-, uno de los mayores atractivos de La Crónica, y bastaba verlo y olerlo, con sus ojitos ácidos y granulados, en desvelo perpetuo, sus ternos replanchados y brillantes, hediondos a tabaco y sudor, de solapas llenas de lamparones y el nudo microscópico de su corbata grasienta, para adivinar que Becerrita era un ciudadano del infierno, que los submundos de la ciudad carecían de secretos para él.

\section{5}

En el prólogo a la reedición de La tía Julia y el escribidor, VLl confiesa que necesitó de la "realidad" (su juventud y joven matrimonio con una tía mayor) para que los melodramas sobregirados de Pedro Camacho, el escribidor boliviano, funcionaran. La mentira necesita algo de realidad. En El pez en el agua, el pasado (la cantera de donde salen sus libros) es lo que explica el presente: la campaña política que, tanto en el libro como en la realidad, parece un melodrama, una ficción, una locura que se desborda. ¿Qué hace Vargas Llosa en una campaña presidencial? Bueno: viviendo una aventura, buscando material para un libro, entre otras cosas. Releyendo El pez en el agua uno se topa con momentos clave que luego van a dar forma a buena parte de sus libros "personales". La única persona que no había aparecido de verdad era su padre, exceptuando una versión exagerada y acaso vengativa en la figura de Fermín Zavala en Conversación en La Catedral, un personaje con mucho más poder y dinero e influencia que el padre real de Vargas Llo- 
sa. La aparición del "verdadero" padre del escritor en El pez en el agua es una auténtica liberación creativa y lo que hace que estas memorias se disparen al cielo y terminen por complementar y potenciar sus otras novelas personales. Y cuando digo personales no las adjetivo así por ser de "jóvenes limeños" sino porque, en efecto, si uno le cree a El pez en el agua y a eso que se llama "la historia real", la vida y los trabajos y todo aquello que Vargas Llosa sí hizo, queda claro que cuando el autor peruano se enfrenta con sus demonios más personales, los resultados son emocionalmente más devastadores que cuando se pone "chancón" e intenta desafíos casi imposibles: La guerra del fin del mundo puede ser una obra maestra pero es una obra maestra fría, kubrickiana incluso, algo que no sucede con, por ejemplo, la nouvelle Los cachorros, donde es más el mundo personal que Vargas Llosa conoció tan bien lo que se eleva a una historia ficticia (en efecto, a un niño lo castró un perro en Lima, aunque de eso Vargas Llosa se enteró por un diario y, en ese sentido, no fue una vivencia personal).

\section{6}

Lo fascinante de La tía Julia y el escribidor es que también se lee como una suerte de "diario de escritura". Aquí está todo lo que necesitamos saber para ir uniendo los puntos de su obra. Es, en ese sentido, su fan book, su libro para los que lo siguen. Veamos esta suerte de guiño a su primer libro: Los jefes:

Yo había visto en esos días una película mexicana (sólo años después sabría que era de Buñuel y quién era Buñuel) que me entusiasmó: Los olvidados. Decidí hacer un cuento con el mismo espíritu: un relato de niños hombres, jóvenes lobeznos endurecidos por las ásperas condiciones de la vida en los suburbios.

Décadas antes de Bolaño, el autor que todo autor-en-ciernes leía o debía leer para encontrar "la ruta a la gloria de las letras" o la fórmula del escritor salvaje, era Vargas Llosa. Estos primeros libros intentaron borrar los límites entre lo real y lo ficticio. Incluso en la notable Historia de Mayta el narrador, sin nombre, es claramente él, aunque ahora parte el día trotando a la largo del malecón de Barranco. Un número no menor de sus obras tratan ese tema: cómo transformarse en creador y 
alejarse del mundo que te tocó. O bien: cómo partir de nuevo y abrazar un mundo y una ideología nuevas. Pero si lo que uno quiere leer es "cómo se logra transformar en escritor" nada mejor que La ciudad y los perros, desde luego, y, por cierto, La tía Julia y el escribidor. Por otro lado, Conversación en La Catedral es la novela cumbre de cómo lograr no convertirse en lo que uno quiere y de cómo la idea de "joderse" depende en buena parte de uno. Sus ensayos sobre otros escritores u otros libros ( La verdad y las mentiras está en los estantes de todo escritor joven y no tan joven latinoamericano) forman parte de este canon sobre "la vida literaria". Leer a Vargas Llosa, pero también enterarse de sus hazañas y aventuras y disputas, gatilló y supongo que aún gatilla a los escritores-en-ciernes la pasión por ser escritor y trazó una ruta que nadie más ofrecía: escribir, escribir, escribir. Disciplina, vocación, huir de tu territorio. Vargas Llosa siempre dejó claro que no era un genio como otros, pero quizás podía acceder a momentos de genialidad. Libros posteriores, como el pedagógico Cartas a un joven novelista, confirman el deseo de VLl de querer ser un referente para los que están iniciándose en la república de las letras, pero ese libro, si bien proviene de la buena literatura, tiene algo innecesario y reiterativo: sus aliados cayeron rendidos ya en Los jefes/Los cachorros. La ciudad y los perros sólo confirmó que uno ya era parte del club Vargas Llosa, que ése era el territorio, que él era la figura a admirar y seguir.

Vargas Llosa inventó la literatura juvenil (no infantil) latinoamericana. Aclaro: no la young adult fiction que ahora vende tanto; no la de los libros de niños ilustrados (aunque ahora editó uno). Vargas Llosa hizo de Miraflores lo que Coppola hizo con Tulsa en "La ley de la calle". Lo suyo no es Crepúsculo ni Harry Potter. Su literatura teen llena de pandillas y gomina no tiene parangón y pocos autores latinoamericanos han sido capaces de conectarse de manera tan visceral con sus lectores, aunque muchos de éstos nunca vuelvan a leerlo a él, o incluso a leer un libro. VLl es el autor masculino-adolescente por excelencia. Los cuentos de Los jefes, esa obra maestra indiscutida del pop y los ritos de iniciación, más esa nouvelle experimental inyectada de testosterona y pop que es Los cachorros (surfistas y tablas hawaianas, bailes y carreras 
en auto, citas a James Dean, relojes Omega y campeonatos de bowling) lo colocan en un lugar de privilegio en los bolsones y mochilas de los estudiantes de enseñanza media. Si a eso le sumamos la novela $\mathrm{La} \mathrm{ciu-}$ dad y los perros (quizás la novela más terrorífica acerca de un colegio que se haya escrito en español), pues estamos ante un "combo" donde el tema es único y es subrayado y exaltado: un hombre puede ser un hombre aunque no sea igual que el resto de los hombres que admira pero que a la vez teme y desprecia. Y si bien el mundo mixto "allá afuera" está lleno de posibilidades, la mujer es un enigma o alguien al borde. Fuera del mundo adolescente de sus primeros libros, el universo vargasllosiano es claramente masculino. Tanto la tía Julia como la niña mala son personajes fascinantes pero imposibles de descifrar para sus coprotagonistas y narradores. En pleno romance con la tía Julia, en el libro que lleva su nombre, Varguitas se escapa por un momento a lo que parece ser algo digno de Pedro Camacho: huye del libro en que está, de la realidad de la radio y su romance clandestino, y capta que aún tiene diecisiete y puede y debe hacer las cosas que están haciendo sus amigos. En el fondo, huye de La tía Julia y el escribidor y se refugia en Los jefes/Los cachorros.

Esa semana que estuve sin ver a la tía Julia, volví a salir varias noches con mis amigos de Miraflores a quienes, desde mis amores clandestinos, no había vuelto a buscar. Eran compañeros de colegio o de barrio, muchachos que estudiaban Ingeniería, como el Negro Salas, o Medicina, como el Colorao Molfino, o que se habían puesto a trabajar, como Coco Lañas, y con quienes, desde niño, había compartido cosas maravillosas: el fulbito y el Parque Salazar, la natación en el Terrazas, las fiestas de los sábados, las enamoradas y los cines. Pero en estas salidas, después de meses sin frecuentarlos, me di cuenta que algo se había perdido en nuestra amistad. Ya no teníamos tantas cosas en común como antes. Hicimos, las noches de esa semana, las mismas proezas que solíamos hacer: ir al pequeño y vetusto cementerio de Surco, para, merodeando a la luz de la luna entre las tumbas removidas por los temblores, tratar de robarnos alguna calavera; bañarnos desnudos en la enorme piscina del balneario Santa Rosa, vecino a Ancón, todavía construyéndose, y recorrer los lóbregos burdeles de la avenida Grau. Ellos seguían siendo los mismos, hacían los 
mismos chistes, hablaban de las mismas chicas, pero yo no podía hablarles de las cosas que me importaban: la literatura y la tía Julia.

Los adolescentes terminan por crecer, al menos la mayoría, claro, y buena parte del éxito de Vargas Llosa es haber establecido, tan temprano, un lazo inquebrantable con sus futuros lectores, imitadores y hasta correligionarios.

\section{8}

Curioso: para ser un escritor/intelectual "a la antigua", análogo, digamos, que teme y duda y más bien desprecia la cultura pop y los medios y el lenguaje chat que han transformado y envilecido el discurso cultural en una suerte de reality donde todo vale y lo relativo se ha vuelto, pues, real, Mario Vargas Llosa - sin quererlo quizás - se ha convertido en una de las figuras más mediáticas de América Latina. ¿Sin quererlo? Quizás sí. No creo que haya sido premeditado, pero después de leerlo durante años, de seguirlo y declararme fan/groupie, de tener que aceptar cierto bullying intelectual por el solo hecho de subrayarlo y no encenderle velas a "Gabo", de usar o robar o colgarme de al menos dos novelas suyas claves que supuran periodismo y no-ficción (Tinta roja que, en su versión cinematográfica, realizada en el Perú, mi personaje de Alfonso Fernández pasa a ser simplemente "Varguitas"), de declarar que quizás la mejor de sus novelas no es estrictamente una novela (El pez en el agua), reitero que sus mejores libros son aquellos donde menos inventó y donde claramente menos investigó. Dicho de otro modo: donde más recordó, donde más ajustó cuentas, donde más se desnudó, donde más vivió lo que no pudo vivir en su momento y quizás quiso (todo esto se encuentra en infinidades de textos de Vargas Llosa, partiendo por su manifiesto La verdad y las mentiras). El "early" Vargas Llosa prueba con creces que la cantera de donde sacaba sus materiales era su propia biografía (de nuevo: El pez en el agua), la cual estaba cruzada con el periodismo que tanto le fascina como repele. Esto me alucina. Entre otras cosas porque estudié periodismo. Para alguien que le tema tanto al periodismo, que le parece el camino recto al fracaso, poca gente como MVLl ha estado tanto en la prensa como sujeto, como colaborador (su columna quincenal es muchas veces más periodismo 
puro y duro que opinión) y ha puesto el periodismo y los periodistas en el centro de su ficción. Vargas Llosa se siente cómodo en los medios y funciona en los medios. Arriba de un escenario, dispuesto a discutir temas políticos o culturales, se transforma en una estrella de rock. Arriba de ciertos escenarios, insólita e inesperadamente, se transforma de hecho en actor, interpretando y narrando cuentos y trozos de novelas, con cambios de vestuario incluido. Pero por mucho que pase buena parte de sus giras (y da la impresión que su vida es una larga gira) conversando con periodistas, usando los medios para defenderse de ataques, es impresionante enfrentarse con el verdadero pánico que siente o que sintió por la figura y la profesión del periodismo. Era otra época, sin duda, una en que el periodismo era eminentemente una carrera masculina, algo sórdida, que se practicaba y desarrollaba de noche.

En esos meses, corriendo entre las mesas de redacción de la oficina de La Crónica, se me vino a la cabeza la idea de ser periodista. Esta profesión, después de todo, no estaba tan lejos de aquello que me gustaba - leer y escribir-, y parecía una versión práctica de la literatura. ¿Por qué objetaría mi padre el que yo fuera un periodista? ¿No lo era él, en cierto modo, al trabajar en la International News Service? Y, en efecto, la idea de que fuera periodista no le pareció mal.

Esto lo cuenta en El pez en el agua pero podría ser un trozo de Conversación en La Catedral. A su padre no le pareció tan mala idea pero al poco rato tanto a Vargas Llosa como a Santiago Zavala le pareció fatal: pues el periodismo estaba intrínsecamente ligado a la bohemia y la bohemia a la noche, a la droga, a los prostíbulos y, peor aún, a la mediocridad, donde la meta era "golpear" al tabloide de la competencia o amistarse con criminales y no transformarse en un novelista de renombre. Vargas Llosa rápidamente captó que escribir para un diario poco y nada tenía que ver con escribir a diario.

Los tres meses que trabajé en La Crónica, entre el cuarto y el último año de secundaria, provocarían grandes trastornos de mi destino. Allí aprendí, en efecto, lo que era el periodismo, conocí una Lima ignota hasta entonces para mí, y por primera vez, hice vida bohemia. Si se piensa que no había cumplido aún dieciséis años — los cumplí ese 28 de marzo-, la impaciencia con la que quise dejar de ser adolescente, llegar a adulto, en el verano de 1952 quedó recompensada. 
[...] He evocado en mi novela Conversación en La Catedral, con los inevitables maquillajes y añadidos, aquella aventura.

Ese verano el jovencísimo aprendió muchas cosas entre esos hombres, pero lo más importante fue huir de ellos.

Entre los jirones del centro de Lima y los bares de mala muerte de La Colmena, Vargas Llosa conoció a mucha gente culta, lectores voraces, que partieron deslumbrándolo pero que, al poco tiempo, se transformaron en una suerte de signos de cede el paso. Escribe en El pez en el agua:

[D]ebo a mi amigo Carlos Ney, en esas noches de bohemia, haberme hecho saber todo lo que yo desconocía sobre libros y autores que andaban por ahí, en el vasto mundo, sin que yo hubiera oído siquiera decir que existían y haberme hecho intuir la complejidad y riqueza de que estaba hecha esa literatura que para mí, hasta entonces, eran apenas las ficciones de aventuras y algunos cuantos poetas clásicos o modernistas.

[...] Siempre creí que, en algún momento, Carlitos Ney publicaría un libro de poemas que revelaría al mundo ese talento enorme que parecía ocultar y del que, en lo más avanzado de la noche, cuando el alcohol y el desvelo habían evaporado en él toda timidez y sentido autocrítico, nos dejaba entrever unas briznas. Que no lo haya hecho, y su vida haya transcurrido, más bien, sospecho, entre las frustrantes oficinas de redacción de los periódicos limeños y las noches de inquerida bohemia, no es algo que me sorprenda, ahora. Pues la verdad es que, como a Carlitos Ney, he visto a otros amigos de juventud, que parecían llamados a ser los príncipes de nuestra república de las letras, ir inhibiéndose y marchitando, por esa falta de convicción, ese pesimismo prematuro y esencial que es la enfermedad por excelencia, en el Perú, de los mejores, una curiosa manera, se diría, que tienen los que más valen de defenderse de la mediocridad, las imposturas y las frustraciones que ofrece la vida intelectual y artística en un medio tan pobre.

Carlitos Ney, junto a otros personajes reales como Raúl Deustua, se transforma en "Carlitos" en Conversación: 
- Trata de escribir poemas después de meterte en la cabeza esas formulitas - dijo Carlitos-. Hay que ser loco para entrar a un diario si uno tiene algún cariño por la literatura, Zavalita.

En la boîte Negro-Negro, tapizada con carátulas de The New Yorker, donde iban "pintores y escritores náufragos", el Carlitos real o el Carlitos ficticio le abre los ojos a Varguitas/Vargas Llosa. Santiago Zavala no alcanza a salvarse; se jode. Zavala es la fantasía que Vargas Llosa tiene de sí mismo si se hubiera quedado en Lima y en La Crónica. Escribe en Conversación:

- Iba a ser escritor, iba a publicar poemas — dijo Carlitos- Entré a La Crónica y cambié de vocación.

— ¿Prefieres el periodismo a la literatura? - dijo Santiago.

—Prefiero el trago — se rió Carlitos-. El periodismo no es una vocación sino una frustración, ya te darás cuenta.

Mario Vargas Llosa se dio cuenta. Y le dio temor, acaso pánico. Buena parte de sus primeros libros funcionan casi como una suerte de proyección de lo que hubiera sido el destino de Vargas Llosa de quedarse en Lima y seguir en el periodismo intentando ser un escritor. Tanto Santiago Zavala como Varguitas están rodeados de modelos de tipos brillantes (Pedro Camacho entre ellos) que no cumplieron la promesa, que no llegaron a ser lo que dijeron que deseaban ser o que terminaron decepcionando/aterrando al álter ego vargasllosiano. Javier, de La tía Julia, es un buen ejemplo:

Javier era mi mejor amigo y nos veíamos a diario, aunque fuera sólo un momento, para constatar que existíamos. Era un ser de entusiasmos cambiantes y contradictorios, pero siempre sinceros. Había sido la estrella del Departamento de Literatura de la Católica, donde no se vio antes a un alumno más aprovechado, ni más lúcido lector de poesía, ni más agudo comentarista de textos difíciles. Todos daban por descontado que se graduaría con una tesis brillante, sería un catedrático brillante y un poeta o un crítico igualmente brillante. Pero él, un buen día, sin explicaciones, había decepcionado a todo el mundo, abandonando la tesis en la que trabajaba, renunciando a la literatura y a la Universidad Católica e inscribiéndose en San Marcos como alumno de Economía [...] decidió que odiaba la literatura y que hasta la economía resultaba prefe- 
rible a eso. Javier hacía su práctica en el Banco Central de Reserva y siempre encontraba pretexto para darse salto cada mañana hasta Radio Panamericana.

Javier es uno de los tantos fantasmas que Vargas Llosa enfrenta a la largo de sus libros. Losers literarios, gente que pudo tener más pero se dejó estar. Gente que hizo cualquier cosa con sólo no enfrentarse a la página en blanco o a la disciplina (una de las vacunas de VLl ante la mediocridad) y que huían del mundo creativo como de la lepra. Vargas Llosa entendió rápido que, para él, en esos años, la lepra era Lima y los trabajos asociados a las letras. La vida estaba en otra parte (París, Europa), aunque su materia prima base siempre iba a ser local. Pero en esos deambuleos por el mundillo artístico-bohemio-periodístico también se dio cuenta que ése era un mundo novelesco formidable (Camacho, Becerrita) y que toda aventura, que toda investigación, es a la larga un reportaje. Vargas Llosa dejó la redacción de un tabloide pero nunca dejó de usar la estructura madre del periodismo como columna vertebral de casi todas sus novelas. En su mundo, alguien está siempre huyendo o está averiguando sobre otro o, lo que es casi lo mismo, acerca de sí mismo.

\section{OBRAS CITADAS}

Rendón, Silvio. Http://marioelescribidor.blogspot.com.

Vargas Llosa, Mario. Los jefes [1959]. Seix Barral, 1982.

- Conversación en La Catedral [1969]. Alfaguara, 2006.

- Los cachorros. Santillana Ediciones, 1967.

La tía Julia y el escribidor [1977]. Madrid: Alfaguara, edición definitiva, segunda edición, 2001.

- La verdad de las mentiras. Punto de Lectura S.L., 2007.

- El pez en el agua: Memorias. Seix Barral, 1993. 